Korb, S., Telyas, A., Sacks, R. and Duka, A. (2019). "Evaluating Procurement and Production System Strategies using Regional Industry Simulation" In: Proc. $27^{\text {th }}$ Annual Conference of the International. Group for Lean Construction (IGLC), Pasquire C. and Hamzeh F.R. (ed.), Dublin, Ireland, pp. 1229-1240. DOI: https://doi.org/10.24928/2019/0182 . Available at: <www.iglc.net>.

\title{
EVALUATING MULTISKILLING IN RESIDENTIAL CONSTRUCTION PROJECTS USING REGIONAL INDUSTRY SIMULATION
}

\author{
Samuel Korb ${ }^{1}$, Avi Telyas ${ }^{2}$, Rafael Sacks ${ }^{3}$, and Arens Duka ${ }^{4}$
}

\begin{abstract}
The Makerhoods project in Newark NJ, USA, is a planned affordable live/work development for low-income residents. With a background in Lean Manufacturing, and confronted with industry norms of low productivity, extensive subcontracting, unreliable plans, and incomplete information, the developer sought to ways to optimize construction cost, schedule and quality by and minimizing uncertainty and variation and by improving workflow. The developer sought to establish how Lean interventions might improve the performance of the production system that was being designed for the product. Specifically, the challenge was to determine how the concept of producing with laborers reorganized from trade-specific teams into multi-skilled work cells might impact the Makerhoods project, given the reality of the local construction market.

To test these questions, Agent-Based Modelling was used. First, analogs of the local market and project of interest were recreated within the modeling environment. Next, the project delivery techniques were tested to find the highest probability of project success with the lowest band of outcome uncertainty. We hope the results will lead to new ways of approaching project management and potentially to establishment of new types of construction firms (i.e. the "finishing cells" composed of multi-skilled teams capable of completely building an apartment's interior).
\end{abstract}

\section{KEYWORDS}

Batch size, GC, Lean construction, multiskilling, simulation, strategies

\section{INTRODUCTION}

The use of subcontracted labor is a central prevailing paradigm in the modern construction industry (Korb and Ballard 2018), and thus the relationships between the General Contractor (GC) and the subcontractors are of paramount importance to the outcome of the project. The strategies that each of these parties use in advancing the needs of the project

1 PhD Candidate, Virtual Construction Lab, Faculty of Civil and Environmental Engineering, Technion Israel Institute of Technology, Haifa Israel, shmuel.korb@technion.ac.il.

2 Founder, Makerhoods.org, atelyas@makerhoods.org

3 Professor, Faculty of Civil and Environmental Engineering, Technion - Israel Institute of Technology, Haifa Israel, cvsacks@technion.ac.il.

4 Undergraduate Research Assistant; Virtual Construction Lab, Faculty of Civil and Environmental Engineering, Technion - Israel Institute of Technology, Haifa Israel, arens@ campus.technion.ac.il. 
as well as their own individual goals (knowingly or unknowingly) strongly influence the flow and duration of the project (Sacks 2016). At one level the two interact in procurement relationships where work volume is bought and sold (usually to the lowest-cost bidder), but due to the inherently interdependent relationship of works in a construction project, there is also a relationship between stability and resource allocation. Harel and Sacks (2006) examined this dynamic through the lens of game theory at the level of a single subcontractor interacting with a single GC. What is necessary as a next step is the ability to apply these models at a multi-project level to properly capture the emergent industrywide dynamics. This in turn requires simulation within a regional industry context (Korb and Sacks 2018).

Makerhoods is a New York City-based real estate development company with a mission to increase self-employment among low-income entrepreneurs ("Makers") by creating affordable live/work communities (Telyas 2016). A typical project consists of lightindustrial space, usually under 1,000 sf. per tenant, alongside multi-family housing, clustered about a central courtyard which becomes the physical gathering point and marketplace to showcase the Makers' products; an artist's conception appears in Figure 1. The Makerhoods project in Newark, NJ, consists of 66 residential apartments (ranging from studio apartments to three-bedroom in size) in a five-story L-shaped building. The ground floor will house a number of workshops for some of the residents to host their "maker-focused" businesses. Also included on the site is a small shopping area/food court, and a preexisting historic structure on the site will be refurbished as a Center of Entrepreneurship co-working space. The founder of the Makerhoods project (second author of this paper) is a long-time advocate and practitioner of Lean Management (Manrique et al. 2007; Yu et al. 2013), and thus he naturally sought to pursue the implementation of Lean concepts and paradigms in this new venture. Given the constraints that prevailing rental rates in the target area placed on the construction budget, the potential cost reduction from a less wasteful and more productive construction process (i.e. Lean) is seen as key to the project's ambition to deliver extra value without added expense.

The Newark, NJ, Housing Market Area (HMA) consists of Essex County (where Newark is located) and the neighboring Union County (Office of Policy Development and Research 2015). As in any construction market, the limited resource pool of the construction industry put the various constructions projects at odds with one another as they compete for the subcontractors' resources. Competition influences resource allocation behavior, and the outcome of any Lean intervention in procurement or production system design is mutually dependent on the resulting behaviors. This local market dynamic was one that the current research sought to explore, using the Newark area as a case study region. 


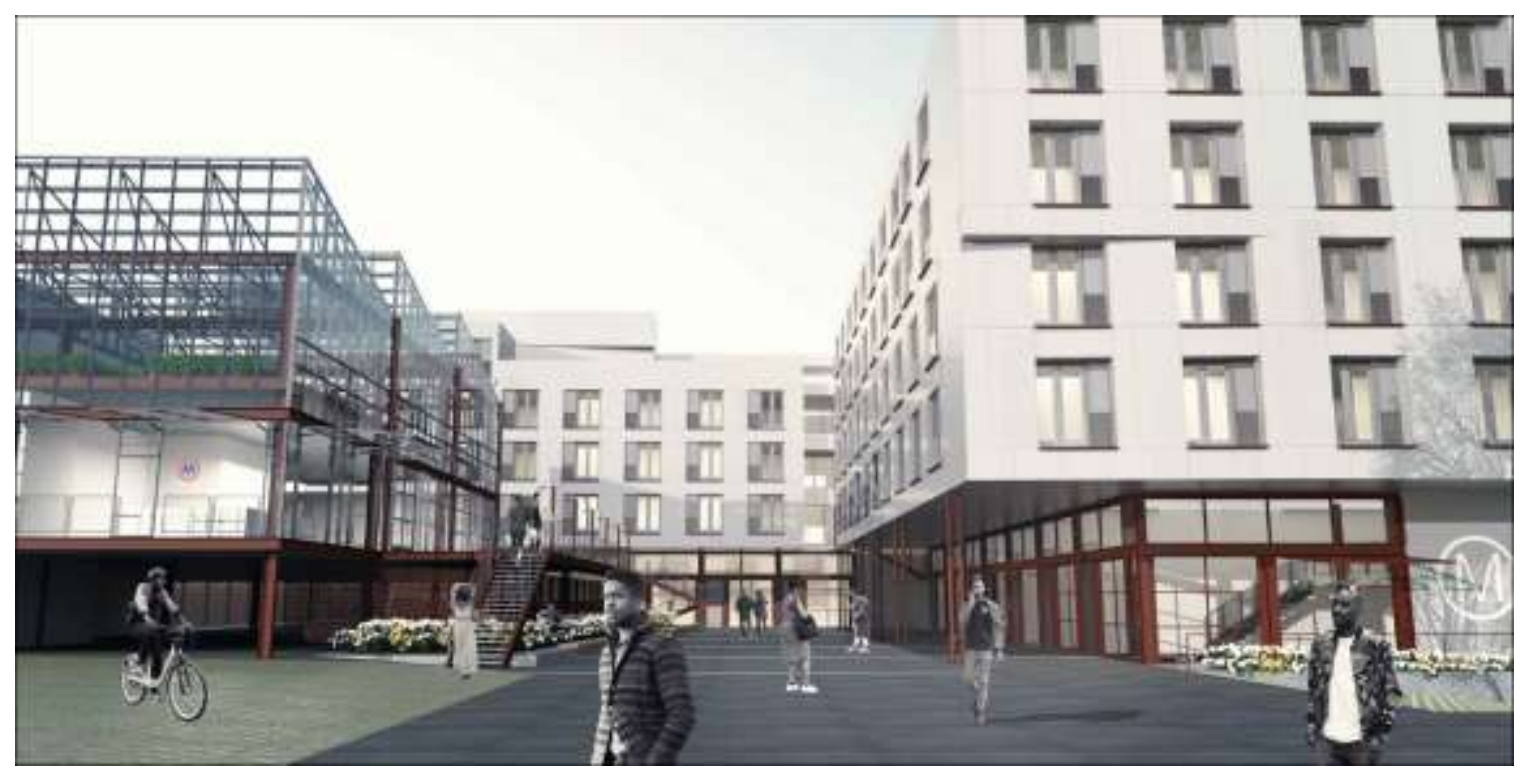

Figure 1: An artist's rendering of the Makerhoods project in Newark, NJ. Workshops are located on the ground floor, residential units on the floors above. To the left is the Food Factory and

Greenhouse. Credit: Makerhoods

The goal for the analysis to explore the impact on the project, and on the local industry, of using multi-skilled labor instead of traditional subcontractors each specializing in a particular trade. These multi-skilled crews can work on a comprehensive scope of activities following the cell production paradigm (Black and Hunter 2003).

By including local/regional information, it should also be possible to analyse systemwide perturbations and point in the direction of more resilient projects. Simulation creates a "sandbox" environment in which it is possible to review the impact of several delivery methods on a project and serves as a tool for designing a project plan in that light such that the probability of success is maximized.

The main purpose of a simulation that includes the owner's project as well as other projects in the area is that it allows the inclusion of regional variables and regional market dynamics in planning, which in turn fosters understanding the meta-project dynamics at work. Every construction project has had to deal with a subcontractor who doesn't show up when planned; very often it is not just an abject dereliction of duty, but rather the subcontractor weighing the pros and cons of their current status and deciding to send the work crews to a different project where they believe their return on investment (of the resources, borne out in profit) will be higher (Sacks and Harel 2006). The meta-project scope afforded by the simulation may help address the root causes of project unreliability.

\section{BACKGROUND}

Construction has persistently experienced low productivity relative to other sectors of the economy, with high levels of waste and untapped value (Egan 1998). Traditional Construction Management Systems (CMS) based on the principles defined in the Project Management Book of Knowledge (PMBOK) (Project Management Institute 2017) have 
not significantly improved productivity, and despite the interest in Lean Construction, this methodology has not yet provoked wide-reaching industry improvement. The reasons are many, but a primary root cause is that information (which forms the basis of all CMS systems) is unreliable and limited in scope. The US military has recognized the difficulty of top down planning in an environment it calls VUCA: Volatility, Uncertainty, Complexity, and Ambiguity (U.S. Army Heritage \& Education Center 2018). All of these terms are applicable to the reality facing construction professionals, and in a VUCA context information quality is not likely to improve in the foreseeable future. This means that new approaches are needed.

Manufacturing techniques hold the promise of order-of-magnitude increases in productivity, but attempts to introduce a production mindset to construction sites have not yet delivered on this promise. Construction is planned as a system, but in reality, given local and regional variables, it is a system of systems and a resilient project delivery method must take these dynamic variables into account if it is to succeed. One way to improve the Construction Management System (CMS) is to divide projects into smaller, more visible and manageable work packages (i.e. locations, scopes, Work Breakdown Structure [WBS], chunks) that localize and decouple the risk wherever possible (Kenley and Seppänen 2010). For this approach to work, the work packages must be independent of one another and have some form of redundancy. Then, these smaller packages of work can be "fed" to multiskilled teams of workers (Sacks and Goldin 2007), which function as small independent work cells. While construction cannot be as precisely tuned to the level of optimization as is the norm in a Toyota plant manufacturing cars, by dividing the work into smaller, humancentered "chunks" and decoupling dependent tasks (adding redundancy wherever possible), the "flow" of the construction line can be improved (Sacks 2016). If shocks to the system are inevitable, then a system designed to localize and minimize the negative impact of the shocks can prevent them from propagating through the system in a chain reaction.

The prevailing strategy in construction subcontracting is to choose the lowest price bid, and the typical contract is based on "piece work" - payment for set work volume, with no stipulation for the quantity of resources consumed or the exact timing of the work unit. In this scenario, subcontractors have an incentive to achieve high productivity when they are on site, even if this means delaying the project progression as they wait for a backlog of work to build up (Sacks and Harel 2006).

Simulation has been used in the past as a research tool in construction management, since it provides insights that the complex realities of a real-life experiment on a construction site might muddle. In addition to the inability to control all of the input variables or isolate their impact, other benefits of simulation include the scope of work in a real situation, the inability to maintain control in real-life experiments, and experimental studies that are sufficiently similar. Examples of simulation being used to explore construction management dynamics include the Parade of Trades game (Tommelein et al. 1999) which examined the impact of varying work rates of individual subs on the outcome of the entire project, or the extensive use of Discrete-Event Simulation (DES) such as CYCLONE (Sawhney et al. 1998) and Stroboscope (Martinez 1996), two DES platforms which were developed specifically for construction. Closer afield, work has been done in modelling the GC-sub interaction using both DES (Esquenazi and Sacks 2006; Sacks et al. 
2007) and Agent-Based Modeling (ABM) (Ben-Alon and Sacks 2015, 2017), finding that Lean improvements in the context of a single project tend to improve project cash flow, duration, WIP, and delivery or products according to customer specifications.

Multiskilling (Carley et al. 2003; Nasirian et al. 2019a; b) is an approach in which work resources (in this case, construction tradesmen) are trained to complete larger sections of the work process. This approach creates redundancy in the laborforce (Angelidis et al. 2013; Eitzen et al. 2004), making production systems more flexible. For the purposes of construction, by training workers to carry out more work packages than they currently do in their hyper-specialized trades, it may be possible to unify trades that were previously separate into teams that can be deployed together as a team to serve as "work cell", rapidly completing the work on a given work location by removing the waiting times between the arrivals of the formerly separate crews. Agent-Based Modeling is a simulation approach where individual "agents" are created, each replete with attributes and behaviors, and set loose to interact with each other. One key feature of ABM is the ability to see emergent behavior at the level of the system, behavior that grows out of the collective interactions of the typically much-simpler instructions of the individual agents (Macal 2016; Macal and North 2010).

\section{ALTERNATIVE PRODUCTION SYSTEMS}

In this work, a CMS is proposed that focuses on Cellular Project Delivery (CPD) (Black and Hunter 2003), designed to be resilient, more reliable and easier to manage. The CPD CMS uses the building elements to define the work packages, allowing the Construction Manager (CM) or Owner to concentrate their focus on a limited number of aggregate work efforts (or cells) that are semi-independent of, and sometimes redundant to one other. Each work package is performed with exclusive access to that location, enhancing a transparent understanding of quality and schedule. Handoffs to the next work cell (and transition of the cell members to the next location) are conditioned on the successful outcome of an extensive QC review of the completed work. The CPD system is designed to reduce system variation, which is expected to yield reduced project duration and total cost, through improved productivity.

The Last Planner System (Ballard 2000) constitutes another Lean Construction-related acknowledgement of the ravages of VUCA unchecked, as well as proposed countermeasures to address them. Last Planner does so by pulling only work that is "sound" (i.e. with all prerequisites met, ready to be transformed from planned to done). This approach is not sufficient in and of itself because while the work may start with some degree of certainty when all the prerequisites have been addressed thanks to the efforts of the Last Planner System (LPS), it may or may not end on time (uncertain duration) or at the quality level required. This is due to the lack of standardized work in construction (standardized work, a key concept in Lean) and the fact that the subcontractors may have interruptions to their work (both internal - in the case of unexpected developments - and external - in the case of the subcontractors being pulled out of the work location to go to another location or even another project). 
Despite the marked interest in applying Lean to the field of construction, and except in a few unique situations with highly-motivated teams, Lean Construction has not proven to be a "magic bullet" in reducing VUCA across the industry (Dave et al. 2015; Koskenvesa and Koskela 2012). At root is the fact that it is nearly impossible to smooth out and then automate an unreliable process:

- A lack of standardized work means task durations are difficult to forecast.

- Task dependencies lead to domino-effects of missed targets beyond the local area of emergent problems - the 'ripple' effect, (Thomas and Oloufa 1995).

- Contractual structures can stifle cooperation by creating zero-sum game lose-lose relationships.

- Local factors can further complicate planning, such as an unexpected spike in the cost of a key input to the project.

These strategies include transitioning from single-skilled traditional workers working in sequence one after the other to a market where work is carried out by multi-skilled teams that are able to completely finish the work in the apartments on their own. The hypothesis here is that by removing the interfaces between multiple teams (each of which is a potential point of delay if the next crew doesn't arrive on time), the outcomes will also be improved. This is the creation of work cells comprised of a number of processing steps collocated (in the case of the mobile production line of construction, collocated in time as much as in physical location).

Reducing batch size is a key concept in Lean, and will be tested as a variable in the simulation. The hypothesis is that reducing the size of the batches (work chunks) contracted to the subcontracting teams (in this case, reducing the batch from all the work locations on a floor of the building as is common practices to just a single apartments) will have a commensurate increase in the flow of the process and reduce the overall project duration.

\section{GOALS OF THE SIMULATION}

For the Makerhoods project, the simulation environment was intended to model, to the extent possible, the local construction market. The main parameters are the volume of construction, the range of project types and sizes, the number and type of subcontracting trade crews available to be hired, typical work rates for the trades, and the usual work flow for the prevailing product compositions in the area, etc. In particular, the specific work volumes for the Makerhoods project itself were assessed using the design data for the project (unit size, area of floors or walls, etc.). Once the general scenario was set up, different project delivery strategies that the management can take could be tested.

\section{STRUCTURE OF THE SIMULATION}

To carry out the simulation, we used a multi-site construction management simulation engine called LeapconX (Korb and Sacks 2019) that was compiled in Netlogo, an AgentBased Modeling platform (Wilensky and Rand 2015). A screenshot appears in Figure 2. 


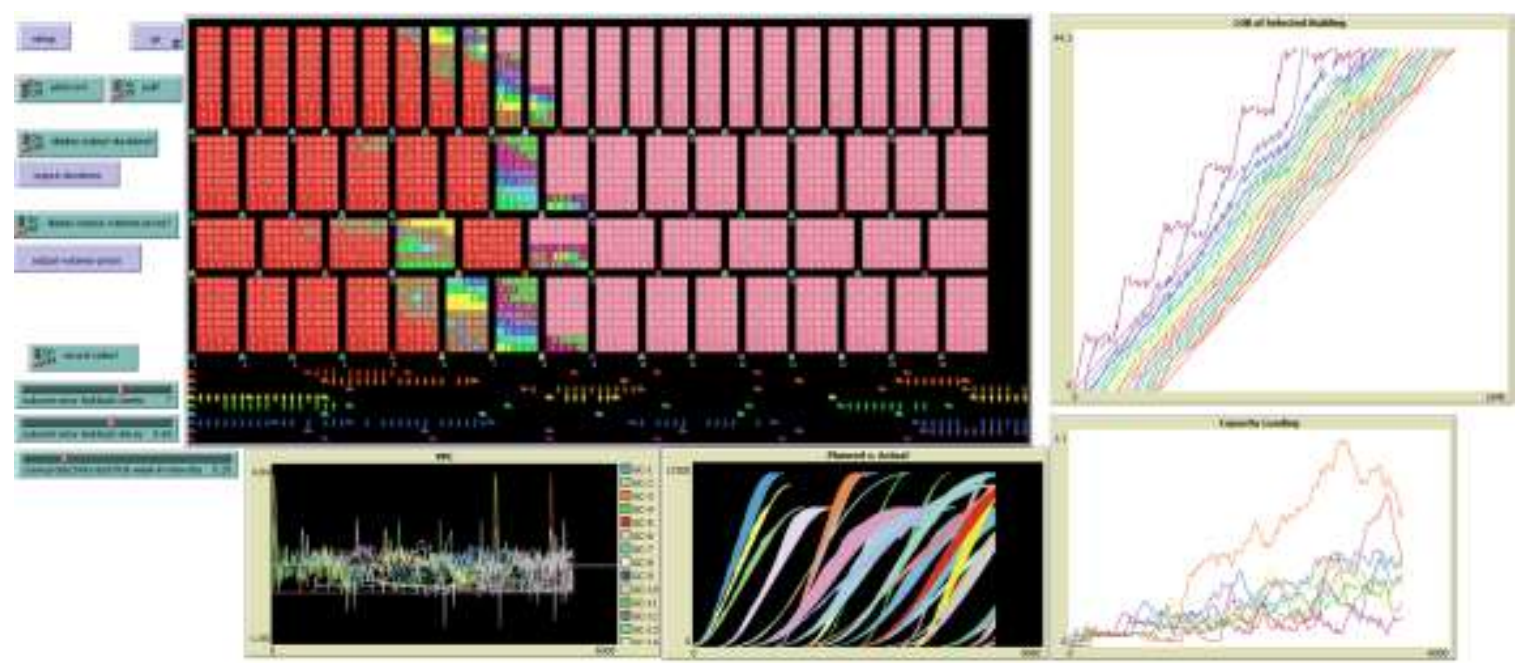

Figure 2: Screenshot of the Multi-site ABM Simulation Platform in Netlogo.

This simulation allows the input of multiple projects in the local market. There are four agents: GCs, Subs, Work Crews, Apartments. Each of the agents in this model has a set of attributes that govern its behavior and the relationships it has with other agents. For example, work crews have a rate of work and number of workers, which govern the amount of work they can do in a given day. They then update the work volume of the apartment they are working in that day, reducing the work remaining of the apartment accordingly.

For each project, the GC negotiates contracts with the subcontractors, each of which has a number of work crews that can be deployed to relevant projects. The color of each subcontractor is the trade, with the work sequence also defined by the sequence of colors of each work package

Of particular interest for this research is the ability to set the strategies the GC will undertake, allowing the evaluation of the outcome for each project relative to the strategies that it employs. Thus the GC has a trait of how many subcontractors it will employ, whether it works in batches or in one-piece flow. The use of multi-skilled teams is a state parameter affecting the entire economy, and thus is not implemented on a GC-by-GC basis.

The "ticks" of the simulation represent a discrete increment of time, and the "week length" relating the number of ticks to a typical work week is a parameter that can be set by the user, allowing the simulation to be run at varying levels of granularity. The start date of each project is another parameter, allowing projects to come online at varying intervals, mimicking the real-life behavior of a local market (new projects begin from time to time). Likewise, the time before beginning the work at which point the GCs will put out a request for bids to the subcontractors and then actually contract with the relevant subs can be tweaked for each project.

Each week, the GC reviews the master schedule for its project, and determines work volumes for each trade that will be required to meet the schedule (as well as closing out any delays that have accumulated). This information is distributed to the subcontractors as the request for weekly work. In turn, the subcontractors collect the requests they have accumulated from the various GCs, and decide where to allocate their work crews. The decision is based on the work requested, but that information is processed based on the 
status of each project, the reliability of the particular GC in the past (i.e. was the GC able to provide the amount of work requested in the previous weeks?), a transfer/travel penalty if a new site is to be opened up, etc. Finally, the crews are distributed to projects based on the sub's best estimate of where the most profit is to be had in the upcoming week.

Once on site, the GCs direct the crews to which work locations to work on, and the crews do their work.

The project specifics for the Makerhoods project (work packages and work volumes) were loaded into the Netlogo model, based on information from the project design (bill of quantities). The rates of work for the trades represented in the project were taken from RSMeans, a database of construction-related data, which offers the ability to drill down from a national (US) level down to a particular city (Gordian 2019). The Residential New Construction data for Newark, NJ were used. The US Census Bureau reports how many apartment units were granted permits on an annual basis in the Newark area for tall buildings (i.e. not single-family homes), and the US Bureau of Labor Statistics provided data for the total labor force for each trade in the same metropolitan area. The 2007 data was used, since that was the most recent full-year data available. The US Department of Housing and Urban Development defines the central submarket of the Newark Housing Market Area as the New Jersey counties of Essex and Union, which includes the city of Newark itself (Office of Policy Development and Research 2015).

A time span of the number of buildings that began construction over the course of two years was chosen as a reasonable balance between computing time and validity of the results, due to the need to overcome the "ramp-up" of the simulation in approximating the relative steady state condition of any real-life construction market. Korb (2019) provides a full description of the simulation and its parameters. A picture of the simulation output mid-run (approximately 1.8 years into the run) appears in Figure 3. The buildings are arranged such that their start date correlates to their location on the $\mathrm{x}$-axis. The location of the buildings on the y-axis is of no consequence and merely allows multiple projects to be portrayed in parallel. As can be seen, at this point the first projects have already been completed (all units are red), and the last ones have not yet begun.

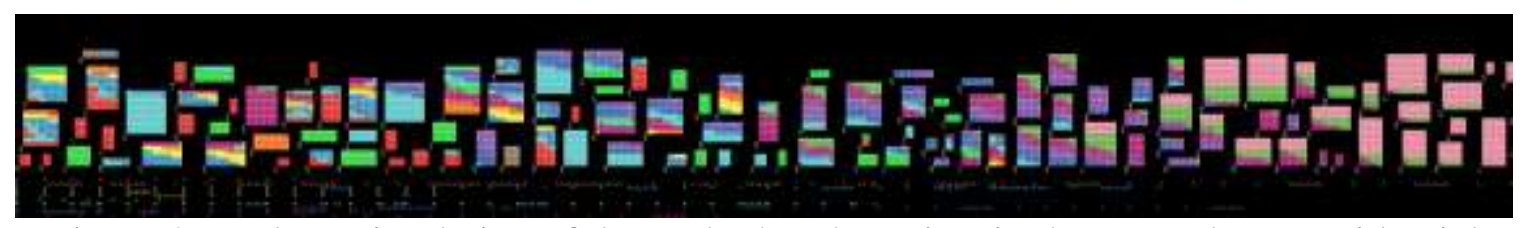

Figure 3: Netlogo simulation of the Makerhoods project in the Newark, NJ residential construction market, using traditional project management methods

Once this scenario was run through the simulation and data were gathered, and then it was re-run as a multi-skilled scenario. In the multi-skilled scenario, all of the work volumes of the work packages are pooled together as a single work package, and each of the subcontractor crews is reassigned from being a specific trade to being multi-skilled. A picture of the multi-skilled, reduced batch-size scenario (with all other data being kept identical) appears in Figure 4. 


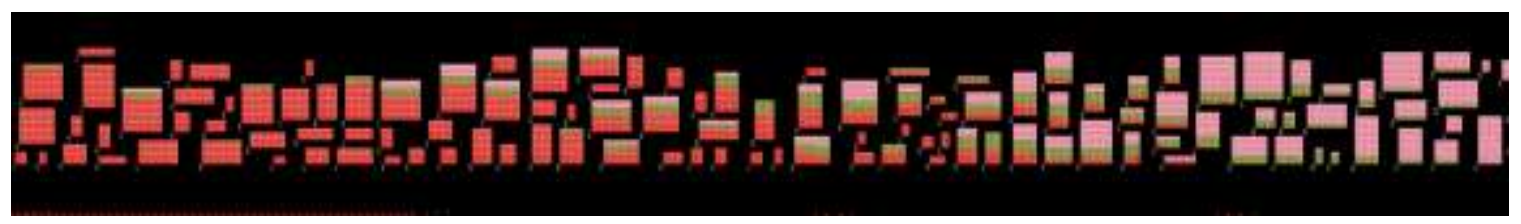

Figure 4: Netlogo simulation of the Makerhoods project in the Newark, NJ residential construction market, using reduced batch size and multi-skilled teams

\section{RESULTS}

Overall, the introduction of multiskilling and reduced batch size served to reduce the overall duration of the simulation run by $8.2 \%$. The average length of the simulated Makerhoods project within this environment was likewise reduced, by $38.7 \%$. This is in line with production theory, such as Little's Law (Hopp and Spearman 2011), which states that a reduction in batch size should lead to a concomitant reduction in the lead time of a project. In addition, the application of multiskilling allowed for greater subcontractor utilization, as there were fewer waiting times created by uneven work durations among the trades.

Another experiment was run to look at the impact of implementing reduced batch size for only the Makerhoods project, assuming all other projects in the simulation use the traditional batching method of releasing a number of apartments together for the exclusive use of one subcontractor. By so doing, it is possible to see the impact of being an "innovator" in the midst of traditionally-managed projects. In the baseline runs, with the Makerhoods project also using batch production control, the average project duration was 3.03 years. Implementing one-piece flow (reduced batch size) lead to a reduction of the project duration to an average of 2.21 years. This represents a time savings of $27.2 \%$, which means improved cash flow for the company and reduced time-dependent project overheads.

\section{CONCLUSION}

This work set out to use a new simulation platform to assess the impact of various Leaninspired strategies that can be applied in a construction project, in an attempt to bring elements of Lean that matured in manufacturing environments to the construction site. A local construction market was re-created within the simulation environment in order to increase the fidelity of the simulation relative to the target project under study, the Makerhoods Newark, NJ project.

Based on the simulation, it is clear that the Makerhoods project would see an improvement in the two key outcome metrics of project duration and project cost if it were to implement the changes discussed above, namely building "work cells" comprised of tradesmen that have the ability to fully complete the work in the work location without the need for multiple entries, exits, coordination among them, etc. The work locations could then be shrunk from batch sizes of a block of apartments on the same floor to a single apartment. This reduction in batch size would further reduce the amount of time required for the project duration by removing a lot of the waiting times in a typical project. 
This simulation and the results indicate that other companies in the field of construction could also benefit from these strategies, and the simulation platform can serve as a good environment in which to test them.

That said, like any result based on simulation, it is necessary to validate the prescriptions in the field, and it is the hope of the authors that the Makerhoods project will do just that. As the Makerhoods project comes to fruition, we will continue to document the impacts of the implementation of these Lean principles.

Future research will explore this simulation tool in greater depth, testing other Lean Construction interventions that GCs can take, to see their effect individually and in combination on project outcomes. The results presented in this paper are thus only the preliminary results of what we hope to be a very insightful line of research. The multiproject nature of the simulation will give us the ability to test not only the effects of the Lean strategies, but also do so at different levels of market adoption, from innovators and early adapters through to a new paradigm in which all players in the new market have adopted the Lean approaches.

\section{REFERENCES}

Angelidis, E., Bohn, D., and Rose, O. (2013). "A simulation tool for complex assembly lines with multi-skilled resources." Simulation Conference (WSC), 2013 Winter, IEEE, 2577-2586.

Ballard, H. G. (2000). “The Last Planner System of Production Control.” The University of Birmingham, Birmingham, UK.

Ben-Alon, L., and Sacks, R. (2015). "Simulating and Vizualising Emergent Production in Construction (EPIC) Using Agents and BIM." 23rd Annual Conference of the International Group for Lean Construction, O. Seppänen, V. A. González, and P. Arroyo, eds., Perth, 371-380.

Ben-Alon, L., and Sacks, R. (2017). "Simulating the behavior of trade crews in construction using agents and building information modeling." Automation in Construction, 74, 12-27.

Black, J. T., and Hunter, S. L. (2003). Lean manufacturing systems and cell design. Society of Manufacturing Engineers, Dearborn, Mich.

Carley, L. A., Haas, C. T., Borcherding, J. D., and Goodrum, P. M. (2003). "Experiences with multiskilling among non-union craft workers in US industrial construction projects." Engineering, Construction and Architectural Management, 10, 374-381.

Dave, B., Hämäläinen, J.-P., and Koskela, L. (2015). "Exploring the Recurrent Problems in the Last Planner Implementation on Construction Projects." Proceedings of the Indian Lean Construction Conference (ILCC 2015), 9.

Egan, J. (1998). Rethinking Construction: Report of the Construction Task Force. HMSO, London, 38.

Eitzen, G., Panton, D., and Mills, G. (2004). "Multi-Skilled Workforce Optimisation." Annals of Operations Research, 127(1-4), 359-372.

Esquenazi, A., and Sacks, R. (2006). "Evaluation of Lean Improvements in Residential Construction using Computer Simulation.” R. Sacks and S. Bertelsen, eds., Catholic University of Chile, Santiago, Chile, 12. 
Gordian. (2019). "RSMeans Data: 2019 Residential New Construction Database." <https://www.rsmeansonline.com> (Nov. 4, 2019).

Harel, M., and Sacks, R. (2006). "Subcontractor Resource Allocation in a Multi-project Environment - Field Study." Understanding and Managing the Construction Process: Theory and Practice, 14th Annual Conference of the International Group for Lean Construction, R. Sacks and S. Bertelsen, eds., Catholic University of Chile, School of Engineering, Santiago, Chile.

Hopp, W. J., and Spearman, M. L. (2011). Factory Physics: Third Edition. Waveland Press.

Kenley, R., and Seppänen, O. (2010). Location-based management for construction: planning, scheduling and control. Spon Press, London; New York.

Korb, S. (2019). "Investigation of Lean Management Methods in the Multi-Customer Construction Industry." PhD Thesis, Technion - Israel Institute of Technology, Haifa, Israel.

Korb, S., and Ballard, H. G. (2018). "Believing is Seeing: Paradigms as a Focal Point in the Lean Discourse." 26th Annual Conference of the International Group for Lean Construction, Chennai, India.

Korb, S., and Sacks, R. (2018). "Towards Multi-Project Simulation of a Lean Production System for Customized Apartment Buildings." Proceedings of the 2018 Winter Simulation Conference, Gothenburg, Sweden.

Korb, S., and Sacks, R. (2019). "Agent-Based Modelling of a Regional Construction Market to Explore General Contractor-Subcontractor Interactions." In preparation.

Koskenvesa, A., and Koskela, L. (2012). "Ten Years of Last Planner in Finland - Where Are We?" 20th Annual Conference of the International Group for Lean Construction, I. D. Tommelein and C. L. Pasquire, eds., San Diego, USA.

Macal, C. M. (2016). "Everything you need to know about agent-based modelling and simulation." Journal of Simulation, 10(2), 144-156.

Macal, C. M., and North, M. J. (2010). "Tutorial on agent-based modelling and simulation." Journal of Simulation, 4(3), 151-162.

Manrique, J. D., Al-Hussein, M., Telyas, A., and Funston, G. (2007). "Constructing a Complex Precast Tilt-Up-Panel Structure Utilizing an Optimization Model, 3D CAD, and Animation." Journal of Construction Engineering and Management, 133(3), 199207.

Martinez, J. C. (1996). "Stroboscope: State and resource based simulation of construction processes." PhD Thesis.

Nasirian, A., Arashpour, M., and Abbasi, B. (2019a). "Critical Literature Review of Labor Multiskilling in Construction.” Journal of Construction Engineering and Management, 145(1), 04018113.

Nasirian, A., Arashpour, M., Abbasi, B., and Akbarnezhad, A. (2019b). "Optimal Work Assignment to Multiskilled Resources in Prefabricated Construction." Journal of Construction Engineering and Management, 145(4), 04019011.

Office of Policy Development and Research. (2015). Comprehensive Housing Market Analysis: Newark, New Jersey-Pennsylvania. U.S. Department of Housing and Urban Development. 
Project Management Institute (Ed.). (2017). A guide to the project management body of knowledge / Project Management Institute. PMBOK guide, Project Management Institute, Newtown Square, PA.

Sacks, R. (2016). "What constitutes good production flow in construction?" Construction Management and Economics, 34(9), 641-656.

Sacks, R., Esquenazi, A., and Goldin, M. (2007). "LEAPCON: Simulation of Lean Construction of High-Rise Apartment Buildings." Journal of Construction Engineering and Management, 133(7), 529-539.

Sacks, R., and Goldin, M. (2007). "Lean Management Model for Construction of HighRise Apartment Buildings." Journal of Construction Engineering and Management, 133(5), 374-384.

Sacks, R., and Harel, M. (2006). "An economic game theory model of subcontractor resource allocation behaviour." Construction Management and Economics, 24(8), 869881.

Sawhney, A., AbouRizk, S. M., and Halpin, D. W. (1998). "Construction project simulation using CYCLONE." Canadian Journal of Civil Engineering, 25(1), 16-25.

Telyas, A. (2016). Makerhoods: Creating Economic Opportunity through Communities. TEDx Jersey City.

Thomas, H. R., and Oloufa, A. (1995). "Labor Productivity, Disruptions and the Ripple Effect." Cost Engineering, 37, 49-54.

Tommelein, I. D., Riley, D. R., and Howell, G. A. (1999). "Parade Game: Impact of Work Flow Variability on Trade Performance." Journal of Construction Engineering and Management, 125, 304-310.

U.S. Army Heritage \& Education Center. (2018). "Who first originated the term VUCA (Volatility, Uncertainty, Complexity and Ambiguity)?” USAHEC Ask Us a Question.

Wilensky, U., and Rand, W. (2015). An introduction to agent-based modeling: modeling natural, social, and engineered complex systems with NetLogo. The MIT Press, Cambridge, Massachusetts.

Yu, H., Al-Hussein, M., Al-Jibouri, S., and Telyas, A. (2013). "Lean Transformation in a Modular Building Company: A Case for Implementation." Journal of Management in Engineering, 29(1), 103-111. 